CLINICAL STUDY

\title{
Lower plasma adiponectin is a marker of increased intima- media thickness associated with type 2 diabetes mellitus and with male gender
}

\author{
Robin P F Dullaart, Rindert de Vries, Arie van Tol and Wim J Sluiter \\ Department of Endocrinology, University Medical Center Groningen, University of Groningen, PO Box 30.001, 9700 RB Groningen, The Netherlands \\ (Correspondence should be addressed to R P F Dullaart; Email: r.p.f.dullaart@int.umcg.nl)
}

\begin{abstract}
Objective: We tested the extent to which altered plasma adipokine levels may contribute to the increased carotid artery intima-media thickness (IMT) associated with type 2 diabetes mellitus and with male gender, independently of conventional cardiovascular risk factors, insulin resistance, and plasma Creactive protein (CRP).

Design: IMT (mean of three segments of both carotid arteries by ultrasonography), insulin resistance (homeostasis model assessment; $\mathrm{HOMA}_{\mathrm{ir}}$ ), plasma CRP, lipids, adiponectin, leptin, resistin, and tumor necrosis factor- $\alpha$ (TNF- $\alpha$ ) were measured in 84 type 2 diabetic patients and 85 control subjects.

Results: In diabetic patients, IMT $(P<0.001)$, mean arterial pressure $(P<0.001)$, $\operatorname{HOMA}_{\text {ir }}(P<0.001)$, plasma CRP $(P=0.003)$, triglycerides $(P=0.037)$, leptin $(P=0.023)$, resistin $(P=0.003)$, and TNF- $\alpha$ $(P=0.003)$ levels were higher, whereas high-density lipoproteins $($ HDL $)$ cholesterol $(P<0.001)$ and adiponectin $(P<0.001)$ levels were lower compared with control subjects. Plasma adiponectin $(P<0.001)$ and leptin $(P<0.001)$ were substantially lower in men than in women. IMT was positively and independently associated with age $(P<0.001)$, diabetes $(P=0.049)$, and male gender $(P=0.002)$ in a multivariate regression model, not including other variables. Further analyses showed that IMT was positively related to age $(P<0.001)$ and plasma triglycerides $(P=0.038)$ and negatively to adiponectin $(P<0.001)$, without independent effects of diabetes, gender, and $\mathrm{HOMA}_{\mathrm{ir}}$ Conclusions: Increased IMT in type 2 diabetes may in part be explained by lower plasma adiponectin and higher triglycerides, but not by leptin, resistin, and TNF- $\alpha$. The gender effect on IMT is related to lower plasma adiponectin.
\end{abstract}

European Journal of Endocrinology 156 387-394

\section{Introduction}

The increased cardiovascular risk in type 2 diabetes mellitus $(1,2)$ is reflected by a higher carotid artery intima-media thickness (IMT) (3-7), which is an established predictor of coronary heart disease and stroke in older subjects (8). This diabetes-associated increase in IMT is associated with conventional cardiovascular risk factors, such as central obesity, high blood pressure, and dyslipidemia, as well as with insulin resistance (3-7).

The pathogenic role of adipokines in insulin resistance, low grade inflammation and cardiovascular disease is increasingly recognized. Decreased plasma adiponectin levels have been documented in type 2 diabetes mellitus $(9,10)$. Plasma adiponectin levels are inversely related to insulin resistance (10-12), as well as to plasma C-reactive protein (CRP) (13). In contrast, plasma leptin is positively related to insulin resistance and adiposity $(14,15)$. Some studies have shown that plasma resistin is also higher in diabetes (16), although the role of resistin in insulin resistance in humans is controversial (17). Both leptin and resistin are regarded to be pro-inflammatory adipokines, as judged by their associations with CRP $(16,18)$. High plasma levels of tumor necrosis factor- $\alpha$ (TNF- $\alpha$ ), another pro-inflammatory adipokine, have been observed in diabetes as well, in association with insulin resistance (19), and its expression is negatively regulated by adiponectin (11).

Clinical end-point studies have suggested that low plasma adiponectin levels may predict coronary heart disease risk in both non-diabetic and diabetic subjects $(20,21)$. High plasma leptin was associated with incident coronary heart disease in some studies (22), but not in others (23). Furthermore, plasma resistin levels are increased in women with coronary heart disease (24) and may determine the severity of coronary artery calcification (25), whereas high plasma TNF- $\alpha$ levels may predict incident cardiovascular disease in men (26). In keeping with these observations, limited literature data raise the possibility that IMT may also be associated with plasma levels of adipokines. IMT is 
inversely related to plasma adiponectin in adults and obese juveniles (27-29). IMT may also be positively associated with plasma leptin (30) and TNF- $\alpha$ levels (31). Importantly, it is unknown to what extent the increased IMT in type 2 diabetes is related to altered plasma levels of either adiponectin, leptin, resistin or TNF- $\alpha$, independently of conventional risk factors, insulin resistance and plasma CRP.

The present study was carried out to test the hypothesis that the increased IMT in diabetes is related to diabetes-associated abnormalities in plasma adipokine levels. Since adiponectin, leptin and possibly also resistin and TNF- $\alpha$ are subject to a sexual dimorphism, with lower levels in men than in women $(11,32-35)$, we also questioned whether the expected association of higher IMT with male gender (36) was weakened or lost when plasma adipokine levels are taken into account.

\section{Subjects and methods}

The study was approved by the Medical Ethics Committee of the University Medical Center Groningen, and all participants provided written informed consent. Type 2 diabetic patients and control subjects were recruited by advertisement. Diabetes was diagnosed using glucose cut-off values as defined by the WHO. Medical history did not reveal recent illnesses and physical examination did not show pulmonary or cardiac abnormalities. Current smoking, the use of more than three alcoholic beverages per day, previous or current use of lipid lowering drugs, clinically manifest cardiovascular disease, renal function abnormalities (elevated serum creatinine and/or elevated urinary albumin excretion), urinary tract infection (positive urine dipstick for leukocytes or blood), thyroid disorders (abnormal thyroid-stimulating hormone levels, use of thyroxine or antithyroid drugs) and liver function abnormalities (transaminase levels $>1.5$ times the upper normal level) were exclusion criteria. Diabetic patients using insulin or thiazolidinediones were also excluded, but the use of antihypertensive medication was allowed. Body mass index (BMI) was calculated as weight divided by height squared $\left(\mathrm{kg} / \mathrm{m}^{2}\right)$. Systolic and diastolic blood pressure was measured after 15 min rest with a sphygmomanometer in sitting position. Mean arterial pressure (MAP) was calculated as $1 / 3 \times$ systolic $+2 / 3 \times$ diastolic blood pressure. Homeostasis model assessment was taken as a measure of insulin sensitivity (homeostasis model assessment; $\mathrm{HOMA}_{\text {ir }}$ ) using the equation: fasting plasma insulin $\times$ glucose/22.5 (37). All participants were studied after an overnight fast at the Laboratory of Vascular Medicine, while the diabetic patients did not take their usual medication before blood sampling.

The study comprised 84 Caucasian type 2 diabetics and 85 Caucasian control subjects. Gender distribution did not significantly differ between the groups $(P=0.69)$.
In diabetic patients, median diabetes duration was 4.3 (interquartile range, 4.0-6.7) years. In addition to diet, 45 patients were treated with sulfonylureas and 42 with biguanides, either alone or in combination. One patient used acarbose. None of the control subjects and 36 diabetic patients used one or more antihypertensive drugs (mostly angiotensin-converting enzyme inhibitors, angiotensin II antagonists, diuretics and $\beta$-blockers, either as single therapy or in combination). None of the diabetic and three of the non-diabetic women used oral contraceptives $(P=0.34)$.

\section{Carotid IMT measurement}

IMT of the carotid arteries was measured by ultrasonography in the supine position. Well-trained sonographers, not informed about subject disease state, scanned high-resolution B-mode ultrasound images (ACUSON 128 XP, Mountain View, CA, USA) with a $7.5 \mathrm{MHz}$ linear array transducer. Three arterial wall segments in each carotid artery were imaged from a fixed lateral transducer angle at the far wall. The segments scanned were the segment $1 \mathrm{~cm}$ proximal to the carotid dilatation (common carotid artery), the segment between the carotid dilatation and carotid flow divider (carotid bulb) and a $1 \mathrm{~cm}$ segment distal to the flow divider (internal carotid artery). The scans were recorded on S-VHS tape and analyzed off-line by an independent image analyst, who was unaware of the subjects' characteristics. B-mode image analyses were digitized with a frame grabber (DT286 l; Data Translation, Inc., Marlboro, MA, USA). The image analysis software was developed using an algorithm as developed by Selzer et al. (38). The mean IMT over the six segments of both carotid arteries was calculated and was designated mean IMT. At a mean IMT of $0.80 \mathrm{~mm}$, inter-sonographer variability amounted to $0.05 \mathrm{~mm}$, with an image analyst variability of less than $0.03 \mathrm{~mm}$, corresponding to a total coefficient of variation between 6.3 and $7.3 \%$.

\section{Laboratory measurements}

Venous blood samples for measurement of lipids, apolipoproteins (apos), insulin, CRP and adipokines were collected into EDTA-containing tubes $(1.5 \mathrm{mg} / \mathrm{ml})$ after overnight fasting and were immediately placed on ice. Plasma was obtained by centrifugation at $1400 \boldsymbol{g}$ for $15 \mathrm{~min}$ at $4^{\circ} \mathrm{C}$. Glucose was measured shortly after blood collection. Samples for other assays were kept frozen at $-80{ }^{\circ} \mathrm{C}$ until analysis.

The high-density lipoprotein (HDL) fraction was separated by precipitation of apo B-containing lipoproteins with polyethylene glycol-6000. Plasma cholesterol, triglycerides and cholesterol in the HDL fraction were assayed by routine enzymatic methods (Roche/Hitachi cat. nos 11876023 and 11875540 respectively, Roche Diagnostics $\mathrm{GmbH}$ ). Non-HDL cholesterol was calculated 
as the difference of plasma total cholesterol-HDL cholesterol. Apo A-I and apo B were measured by immunoturbidimetry (Roche/Cobas Integra Tina- quant cat. nos 03032566 and 03032574 respectively, Roche Diagnostics GmbH).

Plasma total adiponectin, leptin, resistin and TNF- $\alpha$ were assayed using Luminex xMAP technology with commercially available kits, according to the manufacturer's instructions (Linco Research Inc., St Charles, MO, USA, Lincoplex panel A cat. no. HADK1-61K-A and panel B cat. no. HADK2-61K-B, purchased from Nuclilab Inc., Ede, The Netherlands). Validation experiments have shown that adiponectin, leptin, resistin and TNF- $\alpha$ levels, as measured with this technology, are strongly correlated $(r=0.81-0.99)$ with assay results obtained by enzyme-linked immunoassays obtained from Linco Inc. (data provided by the manufacturer, $(50,51))$.

Glucose was analyzed with an APEC glucose analyzer (APEC Inc., Danvers, MA, USA). Plasma insulin was measured with a microparticle enzyme immunoassay (AxSYM Insulin assay; Abbott Laboratories, Abbott Park, IL, USA). High sensitive-CRP was assayed by nephelometry with a threshold of $0.175 \mathrm{mg} / \mathrm{l}$ (BNII N: Dade Behring, Marburg, Germany). FFAs were assayed by a commercially available kit (Wako Chemicals, Neuss, Germany, cat. no. 999-75406). Glycated hemoglobin $\left(\mathrm{HbA}_{1 \mathrm{c}}\right)$ was measured by high-performance liquid chromatography (Bio-Rad; normal range 4.6-6.1\%).

\section{Statistical analysis}

Data are given in medians (interquartile ranges) and were compared by Mann-Whitney U-tests. Differences in proportions of variables were determined by $\chi^{2}$ analysis. Multiple linear regression analysis with a subsequent backward procedure was used to disclose adjusted and independent relationships between variables. Because of skewed distribution, logarithmically transformed values for $\mathrm{HOMA}_{\mathrm{ir}}$, triglycerides, leptin, resistin, adiponectin, TNF- $\alpha$ and CRP were used. Twosided $P$ values $<0.05$ were considered significant.

\section{Results}

As shown in Table 1, IMT, BMI, systolic and diastolic blood pressure, MAP, fasting glucose, HbA1c, plasma insulin, $\mathrm{HOMA}_{\mathrm{ir}}$ and plasma CRP levels were higher in diabetic compared with control subjects. When comparing all women with all men, IMT was clearly lower in women than in men. IMT was also lower in non-diabetic women than in non-diabetic men, but the gender difference in IMT just failed to reach significance in the diabetic group $(P=0.063)$. Plasma insulin, HOMA $_{\text {ir }}$ and CRP were higher in diabetic women than in diabetic men. CRP was higher than $10 \mathrm{mg} / \mathrm{l}$ in three diabetic patients and one control subject. After exclusion of these four subjects, CRP was still higher in diabetic than in the control subjects $(P=0.002)$.

Plasma total cholesterol was slightly lower in diabetic patients compared with control subjects, but non-HDL cholesterol and apo B levels were not different (Table 2). As expected, plasma triglycerides were higher, whereas HDL cholesterol and apo A-I levels were lower in diabetic patients. HDL cholesterol and apo A-I levels were higher in all women compared with all men, as well in the diabetic and control groups separately. Plasma adiponectin was lower, whereas leptin, resistin and TNF- $\alpha$ levels were higher in diabetic patients. Plasma adiponectin and leptin levels were much higher in all women compared with all men, and these gender differences were also present in healthy subjects and diabetic patients separately. There was no significant gender difference with respect to plasma resistin and TNF- $\alpha$, except for somewhat higher resistin levels in diabetic women.

Table 1 Clinical characteristics, mean carotid artery intima-media thickness (IMT) and plasma C-reactive protein in type 2 diabetic patients and control subjects.

\begin{tabular}{|c|c|c|c|c|c|c|}
\hline & \multicolumn{2}{|c|}{ Type 2 diabetic patients $(n=84)$} & \multicolumn{2}{|c|}{ Control subjects $(n=85)$} & \multirow{2}{*}{$\begin{array}{l}P \text { value } \\
\text { DM vs C }\end{array}$} & \multirow{2}{*}{$\begin{array}{l}P \text { value } \\
M \text { vs F }\end{array}$} \\
\hline & Male $(n=52)$ & Female $(n=32)$ & Male $(n=46)$ & Female $(n=39)$ & & \\
\hline Age (years) & $60(51-65)$ & $60(56-67)$ & $57(51-66)$ & $50(44-59)$ & 0.062 & 0.059 \\
\hline IMT (mm) & $0.88(0.78-1.04)$ & $0.80(0.74-0.95)$ & $0.84(0.75-0.91)$ & $0.72(0.68-0.79)^{\dagger}$ & 0.002 & $<0.001$ \\
\hline BMI $\left(\mathrm{kg} / \mathrm{m}^{2}\right)$ & $27.0(24.8-30.9)$ & $29.7(25.4-33.6)$ & $25.8(23.6-27.7)$ & $24.7(22.3-26.9)$ & $<0.001$ & 0.86 \\
\hline Systolic blood pressure $(\mathrm{mmHg})$ & $142(123-155)$ & $146(133-167)$ & $128(118-139)$ & $128(118-146)$ & $<0.001$ & 0.44 \\
\hline Diastolic blood pressure $(\mathrm{mmHg})$ & $85(78-92)$ & $86(82-96)$ & $82(78-88)$ & $78(72-90)$ & 0.004 & 0.91 \\
\hline MAP $(\mathrm{mmHg})$ & $103(95-111)$ & $107(100-117)$ & 97 (92-105) & $99(87-110)$ & $<0.001$ & 0.65 \\
\hline Fasting glucose (mmol/l) & $8.3(7.4-9.3)$ & $8.5(7.2-11.0)$ & $5.8(5.1-6.2)$ & $5.4(5.0-6.1)$ & $<0.001$ & 0.12 \\
\hline $\mathrm{HbA}_{1 \mathrm{c}}(\%)$ & $6.6(6.1-7.1)$ & $6.6(6.1-7.6)$ & $5.3(5.0-5.6)$ & $5.2(4.9-5.6)$ & $<0.001$ & 0.23 \\
\hline Plasma insulin (mU/l) & $8.9(5.6-12.9)$ & $12.3(9.2-17.7)^{\dagger}$ & $6.9(4.6-9.0)$ & $5.8(4.6-7.8)$ & $<0.001$ & 0.45 \\
\hline $\mathrm{HOMA}_{\text {ir }}\left(\mathrm{mU} \times \mathrm{mmol} /\left(\mathrm{I}^{2} \times 22.5\right)\right)$ & $3.58(2.11-5.54)$ & $4.38(3.08-7.74)^{*}$ & $1.65(1.10-2.58)$ & $1.42(1.03-1.97)$ & $<0.001$ & 0.99 \\
\hline Plasma CRP (mg/l) & $1.67(0.67-3.89)$ & $2.17(1.45-5.36)^{*}$ & $0.94(0.48-2.08)$ & $1.47(0.54-2.51)$ & 0.003 & 0.061 \\
\hline
\end{tabular}

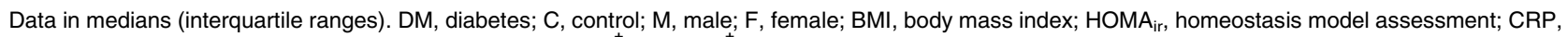
C-reactive protein; MAP, mean arterial pressure. ${ }^{\star} P<0.05 ;{ }^{\dagger} P<0.01 ;{ }^{\ddagger} P<0.001$ from male type 2 diabetic patients or male control subjects. 
Table 2 Plasma lipids, apolipoproteins (apos), adiponectin, leptin resistin and tumor necrosis factor- $\alpha$ (TNF- $\alpha$ ) levels in type 2 diabetic patients and control subjects.

\begin{tabular}{|c|c|c|c|c|c|c|}
\hline & \multicolumn{2}{|c|}{ Type 2 diabetic patients $(n=84)$} & \multicolumn{2}{|c|}{ Control subjects $(n=85)$} & \multirow[b]{2}{*}{$\begin{array}{l}P \text { value } \\
\text { DM vs C }\end{array}$} & \multirow[b]{2}{*}{$\begin{array}{l}P \text { value } \\
M \text { vs } F\end{array}$} \\
\hline & Male $(n=52)$ & Female $(n=32)$ & Male $(n=49)$ & Female $(n=39)$ & & \\
\hline Plasma cholesterol (mmol/l) & $5.14(4.46-5.75)$ & $5.53(5.05-6.13)^{*}$ & $5.71(4.93-6.48)$ & $5.47(5.03-6.43)$ & 0.021 & 0.12 \\
\hline Non-HDL cholesterol (mmol/l) & $4.00(3.37-4.78)$ & $4.13(3.72-4.57)$ & $4.30(3.42-5.12)$ & $3.94(3.51-4.49)$ & 0.56 & 0.44 \\
\hline HDL cholesterol $(\mathrm{mmol} / \mathrm{l})$ & $1.22(1.06-1.45)$ & $1.46(1.20-1.73)^{\dagger}$ & $1.54(1.29-1.71)$ & $1.88(1.51-2.06)^{\ddagger}$ & $<0.001$ & $<0.001$ \\
\hline Plasma triglycerides $(\mathrm{mmol} / \mathrm{l})$ & $1.83(0.96-2.47)$ & $1.54(1.21-2.01)$ & $1.40(0.97-2.10)$ & $1.16(0.87-1.72)$ & 0.037 & 0.16 \\
\hline Plasma apo A-I (g/l) & $1.25(1.13-1.40)$ & $1.50(1.25-1.70)^{\ddagger}$ & $1.37(1.23-1.49)$ & $1.52(1.39-1.65)^{\ddagger}$ & 0.003 & $<0.001$ \\
\hline Plasma apo B (g/l) & $0.89(0.76-1.07)$ & $0.94(0.83-1.06)$ & $0.99(0.80-1.21)$ & $0.86(0.73-0.95)^{*}$ & 0.72 & 0.38 \\
\hline Plasma adiponectin (mg/l) & $12.3(9.0-18.8)$ & $16.6(13.3-28.1)^{*}$ & $16.3(12.6-24.7)$ & $37.4(20.1-52.2)^{\ddagger}$ & $<0.001$ & $<0.001$ \\
\hline Plasma leptin $(\mu \mathrm{g} / \mathrm{l})$ & $4.8(3.3-10.7)$ & $30.1(17.6-34.4)^{\ddagger}$ & $3.8(2.4-5.8)$ & $12.3(5.9-26.9)^{\ddagger}$ & 0.023 & $<0.001$ \\
\hline Plasma resistin $(\mu \mathrm{g} / \mathrm{l})$ & $13.8(9.3-19.8)$ & $17.2(12.4-24.7)^{*}$ & $11.5(8.6-17.5)$ & $11.8(8.5-14.1)$ & 0.003 & 0.56 \\
\hline Plasma TNF- $\alpha(\mathrm{ng} / \mathrm{l})$ & $3.9(2.5-5.2)$ & $3.5(3.0-4.5)$ & $3.1(2.4-4.3)$ & $3.0(2.4-3.5)$ & 0.003 & 0.27 \\
\hline
\end{tabular}

Data in medians (interquartile ranges). DM, diabetes; C, control; M, male; $\mathrm{F}$, female; $\mathrm{HDL}$, high-density lipoproteins. ${ }^{\star} P<0.05 ;{ }^{\dagger} P<0.01 ;{ }^{\ddagger} P<0.001$ from male type 2 diabetic or male control subjects.

In diabetic patients treated with oral hypoglycemic drugs, $\mathrm{HbA}_{1 \mathrm{c}}(6.7$ (6.3-7.6) \%) was higher and plasma adiponectin levels were lower $(13.4(9.1-18.6) \mathrm{mg} / \mathrm{l})$ than in patients treated with diet alone $(\mathrm{HbAlc} 6.1$ (5.4-6.6) \%, $P<0.001$; adiponectin 17.7 (12.9-30.8) $\mathrm{mg} / \mathrm{l}, \quad P=0.005)$. In diabetic patients treated with antihypertensive drugs, MAP (107 (102-115) mmHg) was not significantly different, whereas plasma adiponectin was lower (11.5 (9.1-18.7) compared with patients not using antihypertensive drugs (101 (93-114) mmHg, $P=0.09) ; 15.7$ (12.1-27.9) mg/l, $P=0.04)$.

In diabetic patients, age- and sex-adjusted IMT was positively related to $\mathrm{HOMA}_{\text {ir }}(\beta=0.22, P=0.023)$ and plasma triglycerides $(\beta=0.27, P=0.005)$, and inversely with plasma adiponectin $(\beta=-0.27, P=0.006)$. IMT was not significantly related to MAP, as hemodynamic factor, BMI, plasma CRP, non-HDL cholesterol, HDL cholesterol, plasma leptin, resistin and TNF- $\alpha$ (all $P>$ $0.05)$. In control subjects, age- and sex-adjusted IMT was associated positively with BMI $(\beta=0.27, P=$ $0.002), \mathrm{HOMA}_{\text {ir }}(\beta=0.23, P=0.015)$, plasma triglycerides $(\beta=0.16, P=0.047)$ and again inversely with plasma adiponectin $(\beta=-0.22, P=0.031)$. No significant relationships of IMT with the MAP, plasma CRP, other lipid variables, plasma leptin, resistin or TNF- $\alpha$ were found (all $P>0.05$ ). In both groups, the relationship of IMT with plasma adiponectin remained significant (diabetic patients: $\beta=-0.22, P=0.037$; control subjects: $\beta=-0.19, P=0.045)$ after adjustment for $\mathrm{HOMA}_{\mathrm{ir}}$. Furthermore, in both men and women, IMT adjusted for age and diabetic status was associated inversely with plasma adiponectin (men: $\beta=-0.25, P=0.008$; women: $\beta=-0.35, P=0.002$ ).

In order to disclose which variables could explain the higher IMT in diabetic patients and in men (Table 1), several multiple linear regression analysis models were made using the combined data from the diabetic and the control subjects (Table 3). In model 1, which only includes age, presence of diabetes and gender, it was confirmed that in addition to age, IMT was positively and independently associated with diabetic state and with male gender. In model 2, which also includes other clinical factors (MAP, BMI, and $\mathrm{HOMA}_{\text {ir }}$ ) and plasma CRP as possible determinants of IMT, it was found that the effect of the diabetic state on IMT was attributable to $\mathrm{HOMA}_{\text {ir }}$, but not significantly to MAP, BMI or CRP. In this model, the independent effects of age and gender on IMT remained present. In model 3, which includes lipid variables, the relationship of IMT with diabetes was explained by plasma triglycerides, whereas the relationship of IMT with age and male gender again remained significant. Similar results were obtained in an alternative model, which includes plasma apo B and apo A-I levels instead of non-HDL cholesterol and HDL cholesterol (not shown). In this model, IMT was again associated with plasma triglycerides, without independent contributions from the presence of diabetes, plasma apo B or apo A-I levels (not shown). In model 4, the possible relationships with plasma adipokine levels were examined. In this model, IMT was only significantly related to age and plasma adiponectin without independent contributions from plasma leptin, resistin and TNF- $\alpha$. In model 4, the effects of the diabetic state and gender on IMT were no longer significant. Finally, model 5 was made, which includes age, gender, the presence of diabetes as well as those variables from models $2-4$ with which IMT was significantly associated. This analysis demonstrated that in addition to age, IMT was only independently related to plasma adiponectin and triglycerides. These relationships remained significant (adiponectin, $\beta=-0.18, P=0.017$; triglycerides, $\beta=0.14, P=0.042)$ when the use of oral glucose lowering drugs $(P=0.44)$ and of antihypertensive medication $(P=0.17)$ were accounted for. Similar results were obtained in a model including all variables used in models 1-4 (not shown). Taken together, these analyses thus disclosed that the higher IMT associated with diabetes was attributable to lower plasma adiponectin levels and higher triglyceride levels, and that the 
Table 3 Multiple linear regression models showing statistical determinants of mean carotid artery intima-media thickness (IMT) in type 2 diabetic patients and control subjects $(n=169)$.

\begin{tabular}{|c|c|c|c|c|c|c|c|c|c|c|}
\hline & \multicolumn{2}{|c|}{ Model 1} & \multicolumn{2}{|c|}{ Model 2} & \multicolumn{2}{|c|}{ Model 3} & \multicolumn{2}{|c|}{ Model 4} & \multicolumn{2}{|c|}{ Model 5} \\
\hline & $\beta$ & $P$ value & $\beta$ & $P$ value & $\beta$ & $P$ value & $\beta$ & $P$ value & $\beta$ & $P$ value \\
\hline Age & 0.45 & $<0.001$ & $\begin{array}{l}0.42 \\
\mathbf{0 . 4 5}\end{array}$ & $\begin{array}{l}<0.001 \\
<0.001\end{array}$ & $\begin{array}{l}0.47 \\
\mathbf{0 . 4 9}\end{array}$ & $\begin{array}{r}0.001 \\
<\mathbf{0 . 0 0 1}\end{array}$ & $\begin{array}{l}0.49 \\
\mathbf{0 . 5 2}\end{array}$ & $\begin{array}{l}<0.001 \\
<\mathbf{0 . 0 0 1}\end{array}$ & $\begin{array}{l}0.48 \\
0.52\end{array}$ & $\begin{array}{l}<0.001 \\
<\mathbf{0 . 0 0 1}\end{array}$ \\
\hline DM (yes vs no) & 0.13 & 0.049 & -0.01 & 0.86 & 0.09 & 0.22 & 0.05 & 0.51 & -0.01 & 0.96 \\
\hline Gender (M vs F) & 0.20 & 0.002 & $\begin{array}{l}0.22 \\
0.22\end{array}$ & $\begin{array}{r}<0.001 \\
\mathbf{0 . 0 0 1}\end{array}$ & $\begin{array}{l}0.18 \\
0.19\end{array}$ & $\begin{array}{l}0.01 \\
0.004\end{array}$ & 0.11 & 0.51 & 0.15 & 0.031 \\
\hline $\begin{array}{l}\text { MAP } \\
\text { BMI }\end{array}$ & & & $\begin{array}{r}0.10 \\
-0.02\end{array}$ & $\begin{array}{l}0.16 \\
0.81\end{array}$ & & & & & & \\
\hline Ln HOMA ir & & & $\begin{array}{l}0.23 \\
0.23\end{array}$ & $\begin{array}{r}0.015 \\
<\mathbf{0 . 0 0 1}\end{array}$ & & & & & 0.11 & 0.22 \\
\hline $\begin{array}{l}\text { Ln CRP } \\
\text { Non-HDL choles- } \\
\text { terol }\end{array}$ & & & -0.04 & 0.61 & -0.03 & 0.89 & & & & \\
\hline Ln triglycerides & & & & & $\begin{array}{r}0.23 \\
0.23 \\
-0.02\end{array}$ & $\begin{array}{c}0.01 \\
<0.001 \\
0.83\end{array}$ & & & $\begin{array}{l}0.12 \\
0.15\end{array}$ & $\begin{array}{l}0.099 \\
\mathbf{0 . 0 3 8}\end{array}$ \\
\hline Ln adiponectin & & & & & -0.02 & 0.00 & $\begin{array}{l}-0.29 \\
-0.29\end{array}$ & $\begin{array}{l}0.002 \\
\mathbf{0 . 0 0 0}\end{array}$ & $\begin{array}{l}-0.14 \\
-0.23\end{array}$ & $\begin{array}{l}0.092 \\
0.001\end{array}$ \\
\hline Ln leptin & & & & & & & -0.01 & 0.87 & & \\
\hline Ln resistin & & & & & & & -0.10 & 0.15 & & \\
\hline Ln TNF- $\alpha$ & & & & & & & 0.12 & 0.061 & & \\
\hline
\end{tabular}

$\beta$, standardized regression coefficient; DM, type 2 diabetes mellitus; $\mathrm{F}$, female; M, male; MAP, mean arterial pressure. Independent statistical determinants $(P<0.05)$ are shown in bold. Variables included in the models: Model 1: age, diabetes, and gender. Model 2: age, diabetes, gender, clinical variables, and C-reactive protein (CRP). Model 3: age, diabetes, gender, and lipid variables. Model 4: age, diabetes, gender, and adipokines. Model 5: age, diabetes, gender, and variables with which IMT is independently associated as derived from models 2-4.

higher IMT in men could be explained by lower plasma adiponectin levels.

\section{Discussion}

We documented higher IMT in type 2 diabetic patients, without clinically manifest cardiovascular disease and severe microvascular complications, compared with healthy control subjects. Plasma adiponectin levels were lower, whereas leptin, resistin and TNF- $\alpha$ levels were higher, coinciding with increased adiposity, insulin resistance, higher plasma triglycerides, lower HDL cholesterol and higher CRP levels in the diabetic group. The main new finding of this report is that the increased IMT in diabetes was found to be largely attributable to lower plasma adiponectin, to which IMT was related independently of conventional cardiovascular risk factors, insulin resistance and CRP. Furthermore, our study demonstrates that lower plasma adiponectin concentrations in men may largely account for the gender difference of IMT. No significant relationship of IMT with plasma levels of leptin, resistin or TNF- $\alpha$ was found.

The diabetic state is hallmarked by abnormalities in a cluster of strongly interrelated clinical and metabolic factors that are likely to contribute to increased atherosclerosis susceptibility (39-41). To determine the extent to which IMT was associated with plasma adipokine levels, independently of conventional risk factors, insulin resistance and low grade inflammation, we categorized possible determinants of IMT into clinical variables, including $\mathrm{HOMA}_{\mathrm{ir}}$ and CRP, lipid variables and plasma adipokine levels. Using this somewhat arbitrary approach, which has the advantage that insight is provided into the relative importance of the various factors to which IMT is related, we first found that IMT was associated with either insulin resistance (model 2) or plasma triglycerides (model 3), apart from its expected strong relationship with age and association with gender (36). The effect of mean arterial pressure on IMT did not reach significance. Notably, despite plasma CRP being considered to be a predictor of coronary heart disease risk $(26,42)$, there was no independent relation of IMT with this inflammatory marker, in keeping with a number of previous studies but in contrast to other reports ((43), overviewed in (44)). Furthermore, in the present study, IMT was unrelated to non-HDL cholesterol and plasma apo B levels. This is probably due to the exclusion of subjects using lipid-lowering drugs, which was done in order to obviate effects of such treatment on IMT and plasma CRP. This selection resulted in preferential participation of diabetic patients with a relatively favorable lipid profile. Of the adipokines measured in our study, IMT was only independently related to plasma adiponectin (model 4), at least suggesting that the relationship of IMT with plasma adiponectin is much stronger than that with leptin, resistin and TNF- $\alpha$. The effect of the diabetic state on IMT disappeared when either insulin resistance (model 2) or plasma triglycerides (model 3) was taken into account, concordant with previously 
described effects of these diabetes-associated abnormalities on IMT $(5,7)$. Importantly, both in the diabetic and control subjects separately and in the combined subjects (model 5), IMT was found to be independently related to plasma adiponectin but not to insulin resistance. The inverse relationship of plasma adiponectin with IMT agrees with several other studies $(27-29,45,52)$, although in men this relationship was weakened after adjustment for cardiovascular risk factors (52). In women with variable degrees of glucose tolerance, the relationship of IMT with plasma adiponectin disappeared after adjustment for plasma insulin (45). In our study, IMT was inversely related to plasma adiponectin in both sexes, whereas this relationship was only found in men in another report (52). In Japanese type 2 diabetic patients, IMT was unrelated to plasma adiponectin (31). The reason for this apparent discrepancy is not clear, but may be related to different patient selection, e.g. inclusion of patients with complications, differences in drug treatment, e.g. insulin use, or to genetic differences.

As expected, plasma adiponectin was lower in men compared with women $(11,34,35)$, and this gender difference is most likely attributable to androgen rather than to estrogen/progestagen status (46). In the current survey, this gender dimorphism of plasma adiponectin was present irrespective of diabetic status, whereas an earlier study showed no difference in this adipokine between diabetic men and women (34). Notably, an independent gender effect on IMT remained present in our models accounting for insulin resistance (model 2) and plasma triglycerides (model 3 ) and disappeared only in models that included plasma adiponectin (models 4 and 5). Thus, the present report demonstrates for the first time that lower plasma adiponectin levels, at least in part, explain the higher IMT in men compared with women, and shows that this relationship is independent of insulin resistance and lipid levels.

Our cross-sectional study has possible limitations due to the selection of patients with relatively low plasma lipids, the use of oral blood glucose lowering and antihypertensive medication by many diabetic patients, and the predominant inclusion of middle-aged subjects. Plasma adiponectin was lower in patients receiving medical treatment for glycemic control and high blood pressure, whereas in these patients $\mathrm{HbA}_{1 \mathrm{c}}$ was higher and blood pressure was not lower compared with patients treated with diet alone. This suggests that the use of oral glucose lowering and antihypertensive drugs is associated with adverse consequences of diabetes, rather than with treatment effects per se. Therefore, it is difficult to draw conclusions about the possible confounding effect of these medications on the relationship of IMT with plasma adiponectin, although this association remained present after adjustment for medication. Finally, we measured plasma total adiponectin, rather than its high molecular form, which may be regarded as the most active form of this adipokine.

An increasing body of experimental and clinical evidence supports the possibility that adiponectin may be implicated in the pathogenesis of insulin resistance and in the development of atherosclerosis $(47,48)$. Adiponectin also plays a role in the metabolism of HDL and triglyceride-rich lipoproteins $(12,49)$. Recent intervention studies have demonstrated that regression of IMT by thiazolidinedione treatment coincides with an increase in plasma adiponectin $(53,54)$. The present study agrees with the contention that lower plasma adiponectin levels may be involved in enhanced subclinical atherosclerosis associated with type 2 diabetes mellitus. Obviously, our cross-sectional study cannot provide evidence for a causal relationship.

In conclusion, increased IMT in type 2 diabetes mellitus is associated with lower plasma adiponectin and higher triglycerides. The gender effect on IMT is related to lower plasma adiponectin levels in men.

\section{Acknowledgements}

This study is supported by the Dutch Diabetes Research Foundation (grant 2001.00.012). AM van Roon, PhD, accomplished biotechnical assistance on the IMT measurements off-line IMT analyses of all images were done by GC Teune-Weesjes. The analytical help of B Haandrikman, Endocrine Laboratory, University Medical Center Groningen, for adipokine determination and of LD Dikkeschei, PhD, Isala Klinieken, Zwolle, The Netherlands, for measurement of plasma lipids and apolipoproteins is much appreciated.

\section{References}

1 Kannel WB \& McGee DL. Diabetes and cardiovascular disease: the Framingham study. Journal of the American Medical Association $19792412035-2038$.

2 Haffner SM, Lehto S, Ronnemaa T, Pyorala K \& Laakso M. Mortality from coronary heart disease in subjects with type 2 diabetes and in nondiabetic subjects with and without prior myocardial infarction. New England Journal of Medicine 1998339 229-234.

3 Pujia A, Gnasso A, Irace C, Colonna A \& Mattioli PL. Common carotid arterial wall thickness in NIDDM subjects. Diabetes Care $1994171330-1336$.

4 Niskanen L, Rauramaa R, Miettinen H, Haffner SM, Mercuri M \& Uusitupa M. Carotid artery intima-media thickness in elderly people with NIDDM and in nondiabetic subjects. Stroke 199627 1986-1992.

5 Bonora E, Tessari R, Micciolo R, Zenere M, Targher G, Padovani R, Falezza G \& Muggeo M. Intimal-medial thickness of the carotid artery in nondiabetic and NIDDM patients. Relationship with insulin resistance. Diabetes Care 199720 627-631.

6 Goff DC, D’Agostino RB, Haffner SM, Saad NF \& Wagenknecht LE. Lipoprotein concentrations and carotid atherosclerosis by diabetes status: results from the Insulin Resistance Atherosclerosis Study. Diabetes Care 200023 1006-1011. 
7 Sigurdardottir V, Fagerberg B \& Hulthe J. Preclinical atherosclerosis and inflammation in 61-year-old men with newly diagnosed diabetes and established diabetes. Diabetes Care 2004 27 880-884.

8 O'Leary DH, Polak JF, Kronmal RA, Manolio TA, Burke GL \& Wolfon SK. Carotid-artery intima and media thickness as a risk factor for myocardial infarction and stroke in older adults. Cardiovascular health study collaborative research group. New England Journal of Medicine 1999340 14-22.

9 Hotta K, Funahashi T, Arita Y, Takahashi M, Matsuda M, Okamoto Y, Iwahashi H, Kuriyama H, Ouchi N, Maeda K, Nishida M, Kihara S, Sakai N, Nakajima T, Hasegawa K, Muraguchi M, Ohmoto Y, Nakamura T, Yamashita S, Hanafusa T \& Matsuzawa Y. Plasma concentrations of a novel, adipose-specific protein, adiponectin, in Type 2 diabetic patients. Arteriosclerosis, Thrombosis, and Vascular Biology 200020 1595-1599.

10 Weyer C, Funahashi T, Tanaka S, Hotta K, Matsuzawa Y, Pratley RE \& Tataranni PA. Hypoadiponectinemia in obesity and type 2 diabetes mellitus: close association with insulin resistance and hyperinsulinemia. Journal of Clinical Endocrinology and Metabolism 200186 1930-1935.

11 Kern PA, Di Gregorio GB, Lu T, Rassouli N \& Ranganathan G. Adiponectin expression from human adipose tissue. Relation to obesity, insulin resistance, and tumor necrosis factor- $\alpha$ expression. Diabetes 200352 1779-1785.

12 De Vries R, Wolffenbuttel BHR, Sluiter WJ, Van Tol A \& Dullaart RPF. Post-heparin plasma lipoprotein lipase, but not hepatic lipase activity, is related to plasma adiponectin in Type 2 diabetic patients and healthy subjects. Clinical Laboratory 2005 51 403-409.

13 Shetty GK, Economides PA, Horton ES, Mantzoros CS \& Veves A. Circulating adiponectin and resistin levels in relation to metabolic factors, inflammatory markers, and vascular reactivity in diabetic patients and subjects at risk for diabetes. Diabetes Care 200427 2450-2457.

14 Mantzoros CS, Moschos S, Avramopoulos I, Kaklamani V, Liolios A, Doulgerakis DE, Griveas I, Katsilambros N \& Flier JS. Leptin concentrations in relation to body mass index and the tumor necrosis factor- $\alpha$ system in humans. Journal of Clinical Endocrinology and Metabolism 199782 3408-3413.

15 Abdella NA, Mojiminiyi OA, Moussa MA, Zaki M, Al Mohammedi H, Al Ozairi ESS \& Al Jebely S. Plasma leptin concentration in patients with type 2 diabetes: relationship to cardiovascular disease risk factors and insulin resistance. Diabetic Medicine 200522 278-285.

16 McTernan PG, Fisher FM, Valsamakis G, Chetty R, Harte A, McTernan CL, Clark PMS, Smith SA, Barnett AH \& Kumar S. Resistin and type 2 diabetes: regulation of resistin expression by insulin and rosiglitazone and the effects of recombinant resistin on lipid and glucose metabolism in human differentiated adipocytes. Journal of Clinical Endocrinology and Metabolism 200388 6098-6106.

17 McTernan PG, Kusminski CM \& Kumar S. Resistin. Current Opinion in Lipidology 200617 170-175.

18 Ble A, Windham BG, Bandinelli S, Taub DD, Volpato S, Bartali B, Tracy RP, Guralnik JM \& Ferrucci L. Relation of plasma leptin to C-reactive protein in older adults (from the Invecchiare nel Chianti study). American Journal of Cardiology 200596 991-995.

19 Nilsson J, Jovinge S, Niemann A, Reneland R \& Lithell $H$. Relation between plasma tumor necrosis factor- $\alpha$ and insulin sensitivity in elderly men with non-insulin-dependent diabetes mellitus. Arteriosclerosis, Thrombosis, and Vascular Biology 1998 18 1199-1202.

20 Schultze MB, Shai I, Rimm EB, Li T, Rifai N \& Hu FB. Adiponectin and future coronary heart disease events among men with type 2 diabetes. Diabetes $2005 \mathbf{5 4} 534-539$.

21 Sattar N, Wannamethee G, Sarwar N, Tchernova J, Cherry L, Waalace M, Danesh J \& Whincup PH. Adiponectin and coronary heart disease. A prospective study and meta-analysis. Circulation $2006114623-629$.
22 Wallace AM, McMahon AD, Packard CJ, Kelly A, Shepherd J, Gaw A \& Sattar N. Woscops executive committee. Plasma leptin and the risk of cardiovascular disease in the West of Scotland Coronary Prevention study (WOSCOPS). Circulation $20011043052-3056$.

23 Couillard C, Lamarche B, Mauriege P, Cantin B, Dagenais GR, Moorjani S, Lupien P-J \& Despres J-P. Leptinemia is not a risk factor for ischemic heart disease in men. Diabetes Care 1998 21 782-786.

24 Pischon T, Bamberger CM, Kratzsch J, Zyriax BC, Algenstaedt P, Boeing $\mathrm{H}$ \& Windler E. Association of plasma resistin levels with coronary heart disease in women. Obesity Research 200513 1764-1771.

25 Reilly MP, Lehrke M, Wolfe ML, Rohatgi A, Lazar MA \& Rader DJ. Resistin is an inflammatory marker of atherosclerosis in humans. Circulation $2005111932-939$.

26 Tuomisto K, Jousilahti J, Sundvall J \& Salomaa V. C-reactive protein, interleukin- 6 and tumor necrosis factor alpha as predictors of incident coronary and cardiovascular events and total mortality. A population-based prospective study. Thrombosis and Haemostasis 200695 511-518.

27 Pilz S, Horejsi R, Moller R, Almer G, Scharnagl H, Stojakovic T, Dimitrova R, Weihrauch G, Borkenstein M, Maerz W, Schauenstein K \& Mannge H. Early atherosclerosis in obese juveniles is associated with low serum levels of adiponectin. Journal of Clinical Endocrinology and Metabolism $2005904792-4796$.

28 Lo J, Dolan SE, Kanter JR, Hemphill LC, Connelly JM, Lees RS \& Grinspoon SK. Effects of obesity, body composition, and adiponectin on carotid intima media thickness in healthy women. Journal of Clinical Endocrinology and Metabolism 2006 91 1677-1682.

29 Kojima S, Funahashi T, Maruyoshi H, Honda O, Sugiyama S, Kawano H, Soejima H, Miyamoto S, Hokamaki J, Sakamoto T, Yoshimura M, Kitagawa A, Matsusawa Y \& Ogawa H. Levels of the adipocyte-derived plasma protein, adiponectin, have a close relationship with atheroma. Thrombosis Research $2005 \mathbf{1 1 5}$ 483-490.

30 Ciccone M, Vettor R, Pannacciulli N, Minenna A, Bellacicco M, Rizzon P, Giorgino $\mathrm{R} \&$ De Pergola G. Plasma leptin is independently associated with the intima-media thickness of the common carotid artery. International Journal of Obesity and Related Metabolic Disorders 200125 805-810.

31 Matsuda M, Kawasaki F, Yamada K, Kanda Y, Saito M, Eto M, Matsuki M \& Kaku K. Impact of adiposity and plasma adipocytokines on diabetic angiopathies in Japanese type 2 diabetic subjects. Diabetic Medicine 200421 881-888.

32 Havel PJ, Kasim-Karak S, Dubuc GR, Mueller W \& Phinney SD. Gender differences in plasma leptin concentrations. Nature Medicine 19962 949-950.

33 Pfeiffer A, Janott J, Mohlig M, ristow M, Rochlitz H, Busch H, Schatz H \& Schifferdecker E. Circulating tumor necrosis factor alpha is elevated in male but not in female patients with type II diabetes mellitus. Hormone and Metabolic Research 199729 111-114.

34 Putz DM, Goldner WS, Bar RS, Haynes WG \& Sivitz WI. Adiponectin and C-reactive protein in obesity, type 2 diabetes, and monodrug therapy. Metabolism 200453 1454-1561.

35 Yannakoulia M, Yiannakouris N, Bluher S, Matalas AL, KlimisZacas D \& Mantzoros CS. Body fat mass and macronutrient intake in relation to circulating soluble leptin receptor, free leptin index, adiponectin and resistin concentrations in healthy humans. Journal of Clinical Endocrinology and Metabolism 2003 88 1730-1736.

36 Howard G, Sharrett AR, Heiss G, evans GW, Chambless LE, Riley WA \& Burke GL. Carotid artery intimal-medial thickness distribution in general populations as evaluated by B-mode ultrasound. ARIC investigators. Stroke 199324 1297-1304.

37 Matthews DR, Hosker JP, Rudenski AS, Naylor BA, Treacher DF \& Turner RC. Homeostasis model assessment: insulin resistance and beta-cell function from fasting plasma glucose and insulin concentrations in man. Diabetologia $1985 \mathbf{2 8} 412-419$. 
38 Selzer RH, Hodis HN, Kwong-Fu H, Mack WJ, Lee PL, Liu CR \& Liu $\mathrm{CH}$. Evaluation of computerized edge tracking for quantifying intima-media thickness of the common carotid artery from B-mode ultrasound images. Atherosclerosis 1994111 1-11.

39 De Fronzo RA, Bonadonna RC \& Ferrannini E. Pathogenesis of NIDDM. A balanced overview. Diabetes Care 199215 318-368.

40 Schmidt MI \& Duncan BB. Diabesity: an inflammatory metabolic condition. Clinical Chemistry and Laboratory Medicine $2003 \mathbf{4 1}$ 1120-1130.

41 De Vries R, Borggreve SE \& Dullaart RPF. Role of lipases, lecithin:cholesterol acyltransferase and cholesteryl ester transfer protein in abnormal high density lipoprotein metabolism in insulin resistance and type 2 diabetes mellitus. Clinical Laboratory 200349 601-613.

42 Pai JK, Pischon T, Ma J, Manson JE, Hankinson SE, Joshipura K, Curhan GC, Rifai N, Cannuscio CC, Stampfer MJ \& Rimm EB. Inflammatory markers and the risk of coronary heart disease in men and women. New England Journal of Medicine 2004351 2599-2610.

43 Bowden DW, Lange LA, Langefeld CD, Brosnihan KB, Freedman BI, Carr JJ, Wagenknecht LE \& Herrington DM. The relationship between C-reactive protein and subclinical cardiovascular disease in the diabetes heart study (DHS). American Heart Journal $20051501032-1038$.

44 Choi SH, Chang HC, Ahn CW, Cho HK, Cha BS, Chung Y-S, Lee KW, Lee HC, Huh KB \& Kim D-J. Is high-sensitivity C-reactive protein associated with carotid atherosclerosis in healthy Koreans? Cardiovascular Prevention and Rehabilitation $200512548-554$

45 Behre CJ, Brohall G, Hulthe J, Wikstrand, \& Fagerberg B. Are serum adiponectin concentrations in a population sample of 64-year-old Caucasian women with varying glucose tolerance associated with ultrasound-assessed atheroslcersosis? Journal of Internal Medicine $2006260238-244$.

46 Böttner A, Kratzsch J, MBüller G, Kapellen TM, Blüher S, Keller E, Blüher M \& Kiess W. Gender differences of adiponectin levels develop during the progression of puperty and are related to serum androgen levels. Journal of Clinical Endocrinology and Metabolism $2004894053-4061$.
47 Goldfine $\mathrm{AB} \&$ Kahn CR. Adiponectin: linking the fat cell to insulin sensitivity. Lancet 2003362 1431-1432.

48 Matsusawa Y, Funahashi T \& Shimomura I. Adiponectin and metabolic syndrome. Arteriosclerosis, Thrombosis, and Vascular Biology 200424 29-33.

49 Vergès B, Petit JM, Duvillard L, Dautin G, Florentin E, Galland F \& Gambert P. Adiponectin is an important determinant of apo A-I catabolism. Arteriosclerosis, Thrombosis, and Vascular Biology 2006 26 1364-1369.

50 Liu MY, Xydakis AM, Hoogeveen RC, Jones PH, O’Brian Smith E, Nelson KW \& Ballantyne CM. Multplexed analysis of biomarkers and the metabolic syndrome in human plasma, using the Luminex-100 system. Clinical Chemistry 200551 1102-1109.

51 DuPont NC, Wang K, Wadhwa PD, Culhane JF \& Nelson EL. Validation and comparison of luminex multiplex cytokine analysis kits with ELISA: determinations of a panel of nine cytokines in clinical sample culture supernatants. Journal of Reproductive Immunology 200566 175-191.

52 Nilsson PM, Engström G, Hedblad B, Frystyk J, Persson MM, Berglund G \& Flyvbjerg A. Plasma adiponectin levels in relation to intima media thickness and markers of insulin resistance. Arteriosclerosis, Thrombosis, and Vascular Biology 200626 2758-2762.

53 Langenfeld MR, Forst T, Hohberg C, Kann P, Lübben G, Konrad T, Füllert SD, Sachara C \& Pfützner A. Pioglitazone decreases carotid intima-media thickness independently of glycemic control in patients with type 2 diabetes mellitus. Results from a controlled randomized study. Circulation $20051112525-2531$.

54 Pfützner A, Marx N, Lübben G, Langenfeld M, Walcher D, Konrad T \& Forst T. Improvement of cardiovascular risk markers by pioglitazone is independent from glycemic control. Results from the PIONEER study. Journal of American Collaboration Cardiology $2005 \mathbf{4 5} 1925-1931$.

Received 16 November 2006

Accepted 3 January 2007 